Research Article

\title{
Auxiliary Piers on Long-Span Specially Shaped Mixed Steel Structure Main Tower Cable-Stayed Bridge: Research on the Impact on the Dynamic Performance
}

\author{
Shanshan Guo $\mathbb{D}^{1},{ }^{1}$ Deyong Cui, ${ }^{2}$ and Shaokun $\mathrm{Ma} \mathbb{D}^{3}$ \\ ${ }^{1}$ Zhengzhou Technology and Business University, Zhengzhou 450000, China \\ ${ }^{2}$ Henan Academy of Building Sciences Co. Ltd., Zhengzhou 450000, Henan, China \\ ${ }^{3}$ Guangxi Key Laboratory of Disaster Prevention and Engineering Safety, Guangxi University, Guangxi 530004, China
}

Correspondence should be addressed to Shaokun Ma; 996989576@qq.com

Received 8 August 2021; Revised 6 September 2021; Accepted 7 September 2021; Published 26 October 2021

Academic Editor: Zhengyang Song

Copyright (C) 2021 Shanshan Guo et al. This is an open access article distributed under the Creative Commons Attribution License, which permits unrestricted use, distribution, and reproduction in any medium, provided the original work is properly cited.

This study investigates the influence of auxiliary piers on the natural frequency, deformation characteristics, displacements of the related parts, and internal forces of a long-span heterogeneous steel-structured main tower cable-stayed bridge. Taking the Guohe Third Bridge in Anhui Province as an example, the software ANSYS was used to establish a three-dimensional finite element model of a cable-stayed bridge, and the dynamic characteristics of a long-span specially shaped hybrid steel structure main tower cable-stayed bridge with auxiliary piers added to single span and double spans were analysed. The results show that when one or three pairs of auxiliary piers are added to a single span, the changes in the natural frequency and deformation characteristics are smaller than those when there are no auxiliary piers. When one or three pairs of auxiliary piers are added to each of the two spans, the natural frequency and deformation characteristics are relatively low. Auxiliary piers induce relatively large changes; the changes with 3 pairs of auxiliary piers for a single span is compared with those with 1 pair for a single span, and 3 pairs and 1 pair of auxiliary piers are added to both spans for comparison. The natural vibration frequency and deformation characteristics exhibit relatively small changes; the presence or absence of auxiliary piers and the number of auxiliary piers have a greater influence on the vertical displacement of the main girder and less influence on the vertical displacement of the main tower. An appropriate number of auxiliary piers are beneficial to the seismic resistance of a cable-stayed bridge, and if the number of auxiliary piers is too large, the seismic capacity of the bridge is reduced; it is recommended that a pair of auxiliary piers be added to both spans to optimize the overall dynamic performance of a cable-stayed bridge. This research method can be used on similar cable-stayed bridges to optimize their dynamic characteristics by setting a certain number of auxiliary piers.

\section{Introduction}

With the innovation of structural analysis theory and the development and utilization of computer software, cablestayed bridges have developed rapidly due to their strong spanning ability, good wind resistance, and ease of maintenance [1]. A specially shaped main tower cable-stayed bridge can improve the landscape effect of a bridge in a city and reflect the characteristics of local arts, history, and culture. This type of bridge is often used [2]. The steel structure has a main tower that is easy to construct in different shapes and is convenient for factory prefabrication.
The advantages of high construction accuracy and fast construction speed have been widely employed in the main tower structures. Due to the special structure of cable-stayed bridges, their large spans, and their importance to traffic engineering, their seismic performance has always been an important topic in the design and construction of cablestayed bridges [3-6].

Under the action of an earthquake, the bearings of cablestayed bridges usually endure a large dynamic axial force, and sometimes, a bearing vacancy phenomenon occurs [7]. Yongxing et al. [8] used an actual two-tower cable-stayed bridge as a background to study the bearing vacancy 
phenomenon of a cable-stayed bridge under the action of an earthquake and the influence of auxiliary piers on the bearing vacancy of the cable-stayed bridge. Under the action of an earthquake, when there are no auxiliary piers on either side of the cable-stayed bridge, the vertical displacement and support pressure of the main girder are relatively large; the addition of an auxiliary pier on each side of the cable-stayed bridge can significantly reduce the vertical displacement and the bearing pressure of the main girder. The collision force between the main beam and the support initially decreases, but as the number of auxiliary piers continues to increase, the vertical reaction force of the support and the vertical displacement of the main beam change minimally. Mei et al. [9] used two-tower, three-tower, and four-tower cablestayed bridges as a foundation and studied the static mechanical properties of cable-stayed bridges with the addition of auxiliary piers. The results showed that setting auxiliary piers on the side spans allow the reduction of the number of towers to a certain extent. The horizontal displacement of the tower top, the midspan deflection and bending moment, and the bending moment of the tower root of the cable-stayed bridge improve the structural rigidity. Xiyao et al. [10] studied the influence of auxiliary piers on the static and dynamic characteristics of a single-tower cable-stayed bridge. Huang et al. [11] took the Xiantao Han River singletower cable-stayed bridge as an example and studied the dynamic characteristics of the bridge through five models, including tower-beam consolidation, tower-beam separation, and the single-span addition of different numbers of auxiliary piers. The results showed that the single-tower bridge with auxiliary piers on the side spans of cable-stayed bridges exhibits better overall structural rigidity to a certain extent and that the number of auxiliary piers has little effect on the structural mode and frequency. Liu [12] studied the dynamic characteristics of bridges by adding auxiliary piers to the side span of a six-tower cable-stayed bridge. The research results are similar to those reported by Mei et al. [9]. Fan [13] analysed the dynamic characteristics of this type of bridge by adding auxiliary piers to the side of the high tower on the basis of a cable-stayed bridge with high and low towers and reached the same conclusions $[11,12]$. Wang et al. [14] studied the static and dynamic performance of a cable-stayed bridge with double vertical tower columns as an example, and the results showed that adding auxiliary piers to the side spans can reduce the horizontal displacement of the tower top of the cable-stayed bridge of the system. The deflection of the main beam effectively restrains the vibration of the main beam and improves the overall rigidity of the structure.

There are many similar studies, but in the current research, related scholars have conducted certain studies on cable-stayed bridges with auxiliary piers, and the dynamic characteristics of long-span specially shaped mixed steel structure main tower cable-stayed bridges have been studied. There are few studies on models based on finite element software, and in-depth research of this nature is necessary to provide a reference for the design of cable-stayed bridges with similar long-span specially shaped hybrid steel structures.
This article takes a long-span specially shaped hybrid steel structure main tower cable-stayed bridge-the Guohe Third Bridge in Anhui Province-as an example, establishes a three-dimensional finite element model of the bridge, and based on this model, sets up auxiliary piers on the main girder single span and two spans. The natural frequency, deformation characteristics, and displacement and internal force of related parts of the structure can provide references for the seismic optimization of similar bridges.

\section{Project Overview and Establishment of the Finite Element Model}

The main bridge span of the Guohe Third Bridge in Anhui is $2 \times 124 \mathrm{~m}$. The total height of the main tower of the third Guohe bridge in Anhui Province is $106 \mathrm{~m}$, and the height above the bridge deck is $86 \mathrm{~m}$. The steel tower column adopts rectangular box section. Among them, the upper tower column adopts all steel tower column with a height of $80 \mathrm{~m}$. The middle tower column is a solid concrete tower column, which is a $6 \mathrm{~m}$ high steel-concrete combined section. The tower columns are arranged vertically along the bridge direction. The width of the upper tower column along the bridge direction is $6.5 \mathrm{~m}$, and the width of the lower tower column changes linearly from $7.0 \mathrm{~m}$ at the bottom edge of the beam to $9.0 \mathrm{~m}$ at the bottom of the tower. The transverse bridge direction of the tower column adopts the curve change line type, and each section adopts the tangent of circular arc line. The outer radius of the upper tower column is $R_{1}=148.75 \mathrm{~m}$, the inner radius is $R_{2}=153.25 \mathrm{~m}$, and the radius of the tower axis is $R_{3}=151.00 \mathrm{~m}$. The stay cable adopts galvanized steel strand, and the main beam adopts prestressed concrete double-sided box girder. The standard section of the steel tower column is $4.5 \mathrm{~m}$ wide in the transverse direction and $6.5 \mathrm{~m}$ wide in the longitudinal direction. The connecting steel plate structure is set in the middle of the left and right tower columns, with a total height of $27.0 \mathrm{~m}$. The inner wall of steel tower column in steel-concrete joint section is connected with concrete by shear nails.

The main tower is made of Q345D steel with elastic modulus $E=206 \mathrm{GPa}$ and density $\rho=7800 \mathrm{~kg} / \mathrm{m}^{3}$, and Poisson's ratio $\mu=0.3$. The middle tower column, lower tower column, and auxiliary pier to be added shall be C50 concrete, with elastic modulus $E=34.5 \mathrm{GPa}$, density $\rho=2500 \mathrm{~kg} / \mathrm{m}^{3}$, Poisson's ratio $\mu=0.25$, and stay cable $\Phi$ S15.2 steel strand ( $\Phi$ S stands for steel strand and $\Phi$ S15.2 refers to the steel strand with nominal diameter of $15.2 \mathrm{~mm}$ twisted by a certain number of galvanized steel wires), and its tensile strength is $1860 \mathrm{MPa}$.

A three-dimensional finite element model of the entire bridge is established based on the software ANSYS. The BEAM189 element is used in all other parts, except the LINK10 element is used for the cable stays. LINK10 element is an axial tension only or compression only rod element. When the tension-only option is used, the stiffness disappears if the element is compressed. This is used to simulate the relaxation of cables or chains. LINK10 element has three degrees of freedom on each node: translation along the $X, Y$, and $Z$ directions of the node coordinate system. Whether only in tension or only in compression, this element does not include bending stiffness, 
but it has the functions of stress stiffness and large deformation. BEAM189 element is suitable for slender stubby/thick beam structure. BEAM189 element is secondary (3-node) 3D beam element. BEAM189 element each node has 6-7 degrees of freedom. The exact number of degrees of freedom depends on KEYOPT(1). When KEYOPT(1) = 0, each node has 6 degrees of freedom. When KEYOPT(1) = 1, the 7th degree of freedom (warpage) is added.

In the static calculation of the cable-stayed bridge, the sag effect of the cable is often considered, and the equivalent elastic modulus is used to replace the actual elastic modulus of the cable material. However, in the dynamic calculation, the elastic modulus of the cable is reduced to the structure. The influence of dynamic characteristics is not obvious, and this parameter is generally not reduced [9]. The elastic modulus of reinforced concrete is modified according to the reinforcement ratio. The main tower is modelled in three sections according to the cross-sectional shape, as shown in Figures 1-3, where the steel concrete and concrete sections are solid rectangular sections. The model is established with the $X$-direction as the longitudinal bridge direction, the $Y$ direction as the transverse bridge direction, and the $Z$-direction as the vertical direction. After the model is meshed, the full bridge has more than 3,900 nodes and more than 2,000 elements $[15,16]$.

This article considers the following five types of structural models. Figures 4-8 are schematic diagrams of the five types of structures.

(1) Consolidation of the tower beams without auxiliary piers, as shown in Figure 4. This model is the actual engineering background.

(2) Consolidation of the tower beams with a pair of auxiliary piers, where the distance between the auxiliary piers and the main tower is $80 \mathrm{~m}$, as shown in Figure 5.

(3) Consolidation of the tower beams with 3 pairs of auxiliary piers. The distances between the auxiliary piers and the main tower are $55 \mathrm{~m}, 80 \mathrm{~m}$, and $105 \mathrm{~m}$, respectively, as shown in Figure 6.

(4) Consolidation of the tower beams with a total of 2 pairs of auxiliary piers, one pair for each span, where the distance between the auxiliary piers and the main tower is $80 \mathrm{~m}$, as shown in Figure 7.

(5) Consolidation of the tower beams with a total of 6 pairs of auxiliary piers, with 3 pairs for each span. The distances between the auxiliary piers and the main tower are $55 \mathrm{~m}, 80 \mathrm{~m}$, and $105 \mathrm{~m}$, respectively, as shown in Figure 8.

\section{Influence of the Presence or Absence of Auxiliary Piers on the Natural Frequency and Deformation Characteristics of the Cable- Stayed Bridges}

The natural frequencies and deformation characteristics of the five models corresponding to Figures 4-8 are compared and analysed, as shown in Tables 1-5.
Table 1 shows that, in the first eight steps of the structure, the first, second, sixth, and seventh steps are bending in the $Y$-direction of the main beam, the third and fourth steps are bending in the $Z$-direction of the main beam, and the fifth step is torsional bending. The 8th step is a combination of $Z$ direction and torsional bending of the main beam, and the overall deformation is relatively simple. Of the deformation characteristics listed in Table 1, all are the deformation characteristics of the main girder, indicating that the rigidity of the main tower is greater than the rigidity of the main girder in actual engineering and that the flexibility of the main tower is less than that of the main girder. It is subject to external dynamic loads, such as wind loads, vehicle loads, or earthquakes. The lower main beam is the weak part of the structure.

Tables 2 and 3 show that for Model 2, the increase in natural frequency relative to Model 1 is within $20 \%$, the maximum increase is $19.4 \%$, followed by $19.0 \%$, and the average increase is $13.7 \%$; for Model 3, relative to Model 1, the natural frequency changes of the 2 nd and 8 th orders are more obvious, the maximum increment is $24.9 \%$, followed by $22.8 \%$, and the average increment is $17.3 \%$. Therefore, when one pair or three pairs of auxiliary piers are added to a single span, the natural vibration frequency of the structure increases to a certain extent compared with that without auxiliary piers, but the increase is smaller.

From Tables 2 and 3, the first to fifth steps of Model 2 are the deformation of the main beam, the sixth and seventh steps are the main tower deformation, and the 8th step is the combined deformation of the main beam and the main tower. The overall deformation is relatively simple. The first, fourth, and seventh steps of Model 3 are the deformation of the main beam, and the fifth, sixth, and eighth steps are the deformation of the main tower. The overall deformation is relatively simple. Compared with Model 1, the deformation characteristics of the structure change to a certain extent when one pair or three pairs of auxiliary piers are added to the single span, but the change is small. As the number of auxiliary piers increases, the order of the deformation of the main tower moves forward, indicating that the relative rigidity of the main beam increases but is still less than the rigidity of the main tower. The auxiliary piers coordinate the rigidity of the main beam and the main tower to a certain extent.

Tables 4 and 5 show that compared with that of Model 1, the natural frequency of Model 4 has a larger increase overall, with a largest increase of $106.0 \%$, followed by $82.3 \%$, a smallest increase of $28.1 \%$, and an average increase of $61.8 \%$, which is much larger than the average increase of $13.7 \%$ of the natural frequency of Model 2 compared with that of Model 1. Compared with that of Model 1, the natural frequency of Model 5 has a larger increase overall, with a largest increase of $113.4 \%$, followed by $88.6 \%$. The minimum increment is $31.1 \%$, and the average increment is $66.9 \%$, which is much larger than the $17.3 \%$ average increment of the natural frequency of Model 3 compared with that of Model 1. Therefore, when the two spans have 1 or 3 pairs of auxiliary piers added, the natural frequency of the structure is significantly increased compared with that without auxiliary piers. 


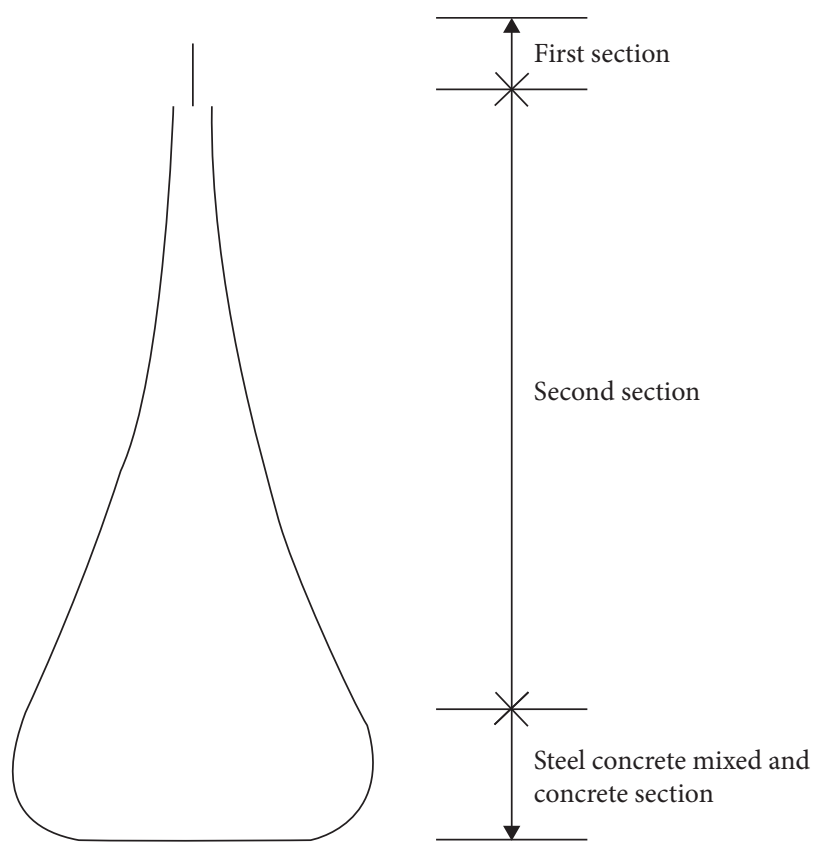

Figure 1: Schematic diagram of the main tower model.

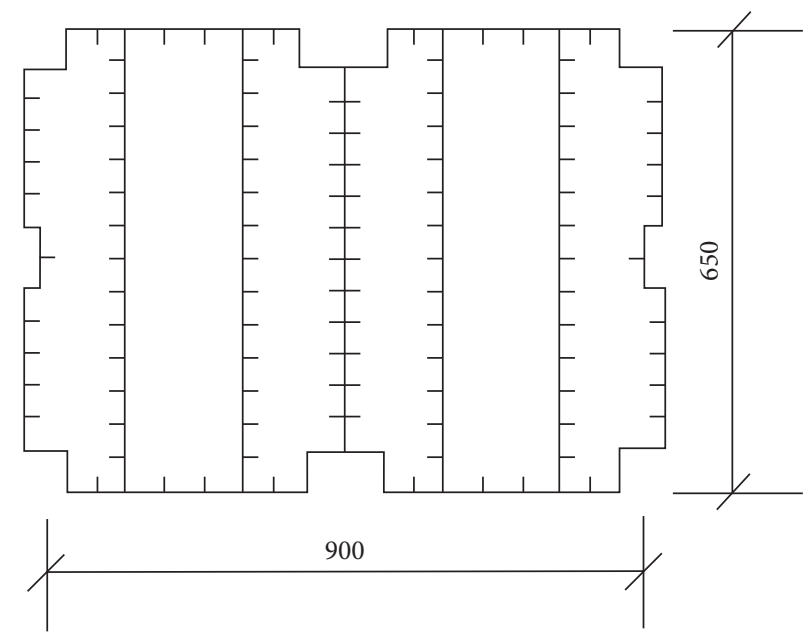

Figure 2: Sectional form of the first section.

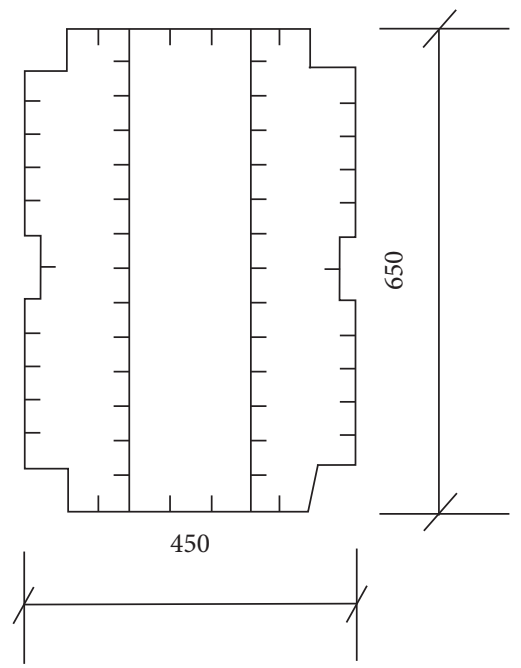

Figure 3: Single-sided cross section of the second section. 


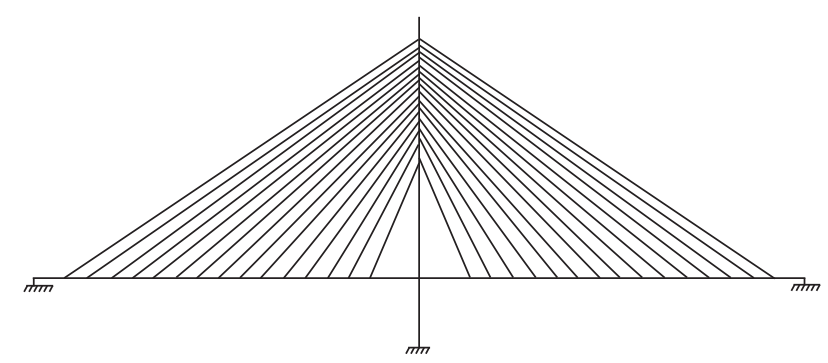

Figure 4: Model 1.

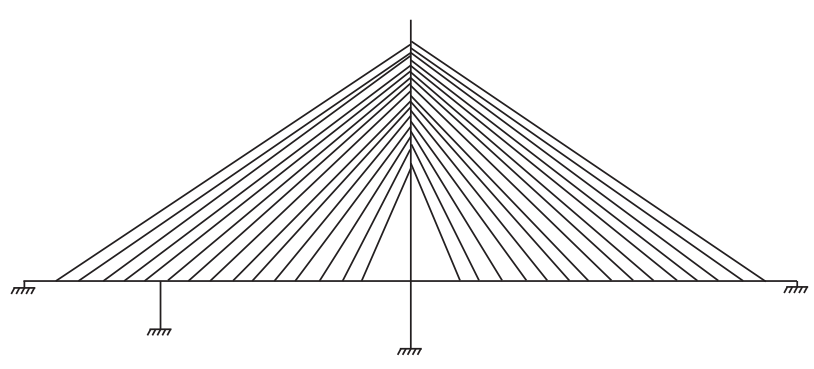

FIgURE 5: Model 2.

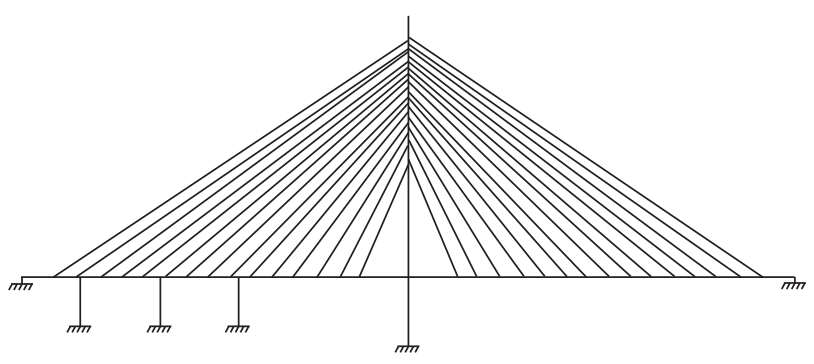

Figure 6: Model 3.

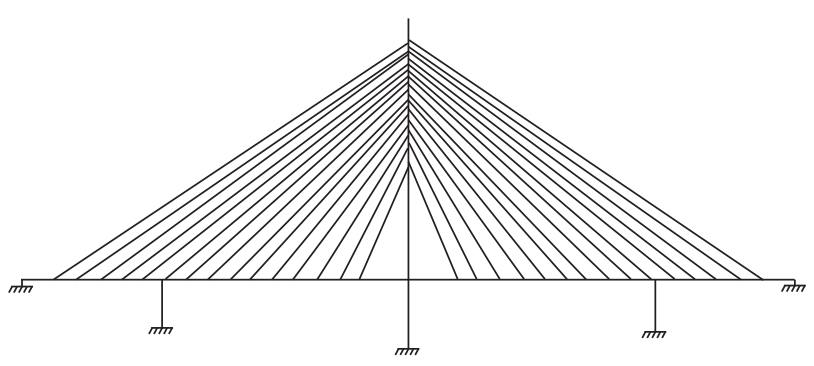

FIgURe 7: Model 4.

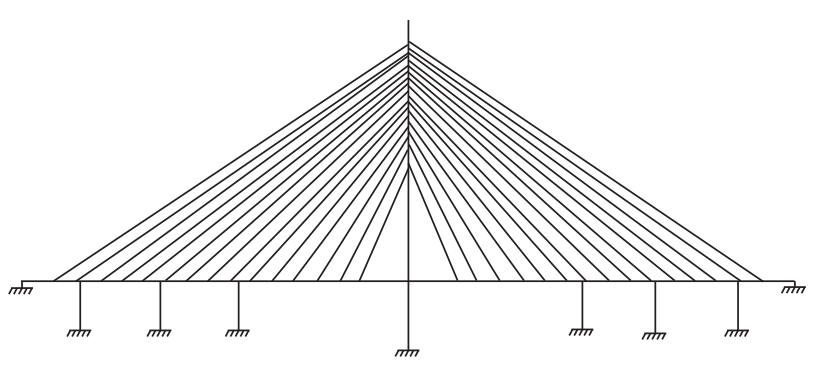

Figure 8: Model 5.
From Tables 4 and 5, the first, second, and sixth steps of Model 4 are the deformation of the main beam, the third and fourth steps are the deformation of the main tower, and the fifth, seventh, and eighth steps are a combination of the deformation of the main beam and the main tower, and the overall deformation is more complicated; the first and seventh steps of model 5 are the deformation of the main beam, the second, third, fifth, and sixth steps are the main tower deformation, and the fourth and eighth steps are a combination of the main beam and the main tower. The overall deformation is more complicated. Compared with Model 1, the deformation characteristics of the structure exhibit a greater change when one pair or three pairs of auxiliary piers are added to each of the two spans, and the degree of change is more obvious than when one pair or three pairs of auxiliary piers are added to a single span. When one pair of auxiliary piers is added to each of the two spans, the deformation of the main beam and the main tower is more uniform, and the rigidity and flexibility of the main beam and the main tower match; when three pairs of auxiliary piers are added to the two spans, the main tower's deformation dominates. The rigidity of the main tower is less than that of the main beam, and the flexibility of the main tower is greater than that of the main beam. The weak parts of the structure are transferred to the main tower.

\section{Influence of the Number of Auxiliary Piers on the Natural Frequency and Deformation Characteristics of Cable-Stayed Bridges}

According to the natural frequencies calculated from the dynamics of Models 2 to 5, the increments of the natural frequencies of Model 3 relative to those of Model 2 and those of Model 5 relative to those of Model 4 are calculated as shown in Table 6.

Table 6 shows that compared with the natural frequency of Model 2, the natural frequency increments of Model 3 are all less than $10 \%$, and the average natural frequency increment is $3.2 \%$, indicating that the natural frequency of the single span increases with 3 pairs of auxiliary piers and that the natural frequency of the single span increases with 1 pair. The increase in natural frequency is small. Compared with the natural frequency of Model 4, the increase in the natural frequency of Model 5 is less than 10\%, and the average increase in the natural frequency is $3.1 \%$, indicating that both spans have increased with 3 pairs. Compared with that with the addition of one pair of auxiliary piers to both spans, the increase in the natural frequency is smaller.

Tables 2 and 3 show that in Model 2, the deformation of the main beam occupies 6 orders, and the deformation of the main tower occupies 3 steps; in Model 3, the deformation of the main beam occupies 5 orders, and the deformation of the main tower occupies 3 orders. Compared with the addition of one pair of auxiliary piers to a single span, the deformation characteristics of the structure exhibit a certain change, but the change is relatively small.

Tables 4 and 5 show that in Model 4, the deformation of the main beam occupies 6 orders, and the deformation 
TABLe 1: The natural frequency and deformation characteristics of Model 1.

\begin{tabular}{lcc}
\hline Order & Natural frequency $(\mathrm{Hz})$ & Deformation characteristics \\
\hline 1 & 0.67 & First-order $Y$-bending of the main beam \\
2 & 0.79 & First-order $Y$-bending of the main beam \\
3 & 1.52 & First-order $Z$-bending of the main beam \\
4 & 1.96 & First-order $Z$-bending of the main beam \\
5 & 1.97 & Torsion and bending of the main beam \\
6 & 2.04 & Second-order $Y$-direction bending of the main beam \\
7 & 2.27 & Second-order $Y$-direction bending of the main beam \\
8 & 2.37 & Main beam second-order $Z$-direction + torsional bending \\
\hline
\end{tabular}

TABle 2: Natural frequency and deformation characteristics of Model 2.

\begin{tabular}{|c|c|c|c|}
\hline Order & $\begin{array}{l}\text { Natural frequency } \\
(\mathrm{Hz})\end{array}$ & $\begin{array}{c}\text { Increment of the natural frequency compared } \\
\text { with that of Model } 1(\%)\end{array}$ & Deformation characteristics \\
\hline 1 & 0.75 & 11.9 & First-order Y-bending of the main beam \\
\hline 2 & 0.94 & 19.0 & First-order Y-bending of the main beam \\
\hline 3 & 1.73 & 13.8 & First-order $Z$-direction bending of the main beam \\
\hline 4 & 2.16 & 10.2 & Torsion and bending of the main beam \\
\hline 5 & 2.21 & 12.2 & Second-order $Y$-direction bending of the main beam \\
\hline 6 & 2.33 & 14.2 & Y-curved main tower \\
\hline 7 & 2.47 & 8.8 & $X$-direction bending of the main tower \\
\hline 8 & 2.83 & 19.4 & $\begin{array}{c}\text { First-order } Z \text {-direction of the main beam }+X \text {-direction } \\
\text { bending of the main tower }\end{array}$ \\
\hline
\end{tabular}

TABle 3: Natural frequency and deformation characteristics of Model 3.

\begin{tabular}{lccc}
\hline $\begin{array}{l}\text { Order } \\
1\end{array}$ & $\begin{array}{c}\text { Natural frequency } \\
(\mathrm{Hz})\end{array}$ & $\begin{array}{c}\text { Increment of the natural frequency compared with that of } \\
\text { Model 1 }(\%)\end{array}$ & Deformation characteristics \\
2 & 0.78 & 16.4 & $\begin{array}{c}\text { First-order } Y \text {-bending of the main beam } \\
\text { First-order } Z \text {-direction bending of the main } \\
\text { beam }\end{array}$ \\
3 & 0.97 & 22.8 & $\begin{array}{c}\text { Second-order } Y \text {-direction bending of the } \\
\text { main beam }\end{array}$ \\
4 & 1.78 & 17.1 & $\begin{array}{c}\text { Torsion of the main beam } \\
5\end{array}$ \\
6 & 2.20 & 12.2 & $Y$-curved main tower \\
7 & 2.26 & 14.7 & $X$-direction bending of the main tower \\
8 & 2.55 & 18.1 & $Y$-direction bending of the main beam \\
& 2.96 & 12.3 & $X$-direction bending of the main tower \\
\hline
\end{tabular}

TABle 4: Natural frequency and deformation characteristics of Model 4.

\begin{tabular}{|c|c|c|c|}
\hline Order & $\begin{array}{l}\text { Natural frequency } \\
(\mathrm{Hz})\end{array}$ & $\begin{array}{l}\text { Increment of the natural frequency compared } \\
\text { with that of Model } 1(\%)\end{array}$ & Deformation characteristics \\
\hline 1 & 1.38 & 106.0 & First-order $Y$-bending of the main beam \\
\hline 2 & 1.44 & 82.3 & First-order $Y$-bending of the main beam \\
\hline 3 & 2.40 & 57.9 & $Y$-curved main tower \\
\hline 4 & 2.51 & 28.1 & $X$-direction bending of the main tower \\
\hline 5 & 3.06 & 55.3 & $\begin{array}{c}\text { First-order } Z \text {-direction of the main beam }+X \text {-direction } \\
\text { bending of the main tower }\end{array}$ \\
\hline 6 & 3.29 & 61.3 & Main beam first-order $Y$-direction + torsional bending \\
\hline 7 & 3.43 & 51.1 & $\begin{array}{l}\text { Main beam first-order } Y \text {-direction }+ \text { main beam } \\
\text { torsion }+ \text { main tower torsion deformation }\end{array}$ \\
\hline 8 & 3.62 & 52.7 & $\begin{array}{c}\text { Second-order } Y \text {-direction of main beam }+Y \text {-direction } \\
\text { bending of the main tower }\end{array}$ \\
\hline
\end{tabular}


TABLE 5: The natural frequency and deformation characteristics of Model 5.

\begin{tabular}{|c|c|c|c|}
\hline Order & $\begin{array}{l}\text { Natural frequency } \\
(\mathrm{Hz})\end{array}$ & $\begin{array}{l}\text { Increment of the natural frequency compared } \\
\text { with that of Model } 1(\%)\end{array}$ & Deformation characteristics \\
\hline 1 & 1.43 & 113.4 & First-order $Y$-bending of the main beam \\
\hline 2 & 1.49 & 88.6 & $Y$-curved main tower \\
\hline 3 & 2.50 & 64.5 & $X$-direction bending of the main tower \\
\hline 4 & 2.57 & 31.1 & $\begin{array}{c}\text { First-order } Y \text {-direction of the main beam }+Y \text {-direction } \\
\text { bending of the main tower }\end{array}$ \\
\hline 5 & 3.13 & 58.9 & $X$-direction bending of the main tower \\
\hline 6 & 3.41 & 67.2 & $Y$-curved main tower \\
\hline 7 & 3.55 & 56.4 & Second-order $Y$-direction bending of the main beam \\
\hline 8 & 3.68 & 55.3 & $\begin{array}{c}\text { Second-order } Y \text {-direction of the main beam }+Y \text {-direction } \\
\text { bending of the main tower }\end{array}$ \\
\hline
\end{tabular}

TABLE 6: The influence of the number of auxiliary piers on the natural frequency of cable-stayed bridges.

\begin{tabular}{|c|c|c|c|c|c|c|c|c|}
\hline Order & 1 & 2 & 3 & 4 & 5 & 6 & 7 & 8 \\
\hline Model 3 vs. Model 2 increment of natural frequency (\%) & 4.0 & 3.2 & 2.9 & 1.9 & 2.3 & 3.4 & 3.2 & 4.6 \\
\hline Model 5 vs. Model 4 increment of natural frequency (\%) & 3.6 & 3.5 & 4.2 & 2.4 & 2.3 & 3.6 & 3.5 & 1.7 \\
\hline
\end{tabular}

of the main tower occupies 5 steps; in Model 5, the deformation of the main beam occupies 4 orders, and the deformation of the main tower occupies 6 orders. Compared with the addition of 3 pairs of auxiliary piers for each of the two spans, the deformation characteristics of the structure exhibit a certain change, but the change is relatively small. The addition of 3 pairs of auxiliary piers to each of the two spans causes the rigidity of the main girder to be greater than that of the main tower, making the rigidity distribution of the cable-stayed bridge unreasonable. Moreover, the addition 3 pairs of auxiliary piers to each of the two spans greatly increases the project cost when optimizing the seismic performance of the structure. Model 5 is not economical, so one pair of auxiliary piers can be added to each of the two spans to optimize the seismic performance of the cable-stayed bridge structure.

\section{Seismic Response Analysis of Cable-Stayed Bridges with Auxiliary Piers Added to Both Spans}

The addition of auxiliary piers to the main girder for both spans has a greater impact on the natural frequency and the corresponding mode shape of the cable-stayed bridge. Therefore, it is necessary to further analyse the seismic response of the cable-stayed bridge when auxiliary piers are added to both spans. That is, further research should be performed on the seismic responses of Model 1, Model 4, and Model 5 under seismic wave excitation.

Currently, the Chinese Bridge Seismic Design Code stipulates that the internal force response caused by seismic fluctuations in various directions should take into account the combination of various working conditions and take unfavourable conditions for seismic design: (1) the transverse bridge direction; (2) longitudinal bridge direction; (3) horizontal bridge direction $+1 / 2$ vertical direction; and (4) longitudinal bridge direction $+1 / 2$ vertical direction.
El Centro seismic waves are used as input for these three models. The seismic wave excitation time is $15 \mathrm{~s}$, and the seismic acceleration step is $0.02 \mathrm{~s}$.

5.1. Seismic Response Analysis of Three Structural Models under the Transverse Bridge Direction and Transverse Bridge Direction $+1 / 2$ Vertical Excitation. The maximum displacement of the tower top and the midspan and the maximum axial force in the midspan of the three structural models under the transverse and cross bridge directions $+1 /$ 2 vertical excitation are shown in Tables 7 and 8, and the maximum bending moments at the root and midspan of the tower are shown in Tables 9 and 10.

Tables 7 and 8 show that under the transverse bridge direction and the transverse bridge direction $+1 / 2$ vertical excitation, the maximum displacement in the transverse direction of the top of Model 4 tower is smaller than the maximum displacement in the transverse direction of the tower top of Model 1. The maximum displacement of the top of the tower in the transverse direction is smaller than that of Model 5. The maximum displacement of the top of the tower in the transverse direction of the structure indicates that the provision of a pair of auxiliary piers on both spans reduces the shock of the main tower, which is beneficial to the seismic resistance of the main tower. In the case of 3 pairs of auxiliary piers, the rigidity of the main girder is greater, and the maximum displacement in the transverse direction of the tower top increases accordingly, which is unfavourable for the seismic resistance of the main tower. Model 1, Model 4, and Model 5 exhibit minimal change in the maximum vertical and vertical displacement of the tower top, indicating that the presence or absence of auxiliary piers and the number of auxiliary piers basically do not affect the maximum vertical and vertical displacement of the tower top.

Tables 7 and 8 show that under the transverse direction and transverse direction $+1 / 2$ vertical excitation, with an increasing number of auxiliary piers, the maximum 
TABle 7: Displacements and axial forces of the three structural models under transverse excitation.

\begin{tabular}{|c|c|c|c|c|c|c|c|}
\hline \multirow{2}{*}{$\begin{array}{l}\text { Structural } \\
\text { model }\end{array}$} & \multicolumn{3}{|c|}{$\begin{array}{l}\text { Maximum displacement of the tower top } \\
\qquad(\mathrm{mm})\end{array}$} & \multicolumn{3}{|c|}{$\begin{array}{c}\text { Maximum displacement in the middle of } \\
\text { the } \operatorname{span}(\mathrm{mm})\end{array}$} & \multirow{2}{*}{$\begin{array}{l}\text { Maximum axial force in the middle } \\
\text { of the span }(\mathrm{kN})\end{array}$} \\
\hline & $\begin{array}{l}\text { Cross } \\
\text { bridge }\end{array}$ & $\begin{array}{l}\text { Longitudinal } \\
\text { direction }\end{array}$ & Vertical & $\begin{array}{l}\text { Cross } \\
\text { bridge }\end{array}$ & $\begin{array}{l}\text { Longitudinal } \\
\text { direction }\end{array}$ & Vertical & \\
\hline Model 1 & 48.50 & 0.003 & 61.31 & 197.02 & 0.74 & 54.71 & $6.29 \times 10^{3}$ \\
\hline Model 4 & 36.72 & 0.003 & 61.27 & 78.56 & 0.76 & 6.24 & $5.68 \times 10^{3}$ \\
\hline Model 5 & 69.21 & 0.006 & 61.58 & 9.85 & 0.70 & 0.41 & $6.87 \times 10^{3}$ \\
\hline
\end{tabular}

Table 8: Displacements and axial forces of the three structural models under the transverse bridge direction $+1 / 2$ vertical excitation.

\begin{tabular}{|c|c|c|c|c|c|c|c|}
\hline \multirow{2}{*}{$\begin{array}{l}\text { Structure } \\
\text { type }\end{array}$} & \multicolumn{3}{|c|}{$\begin{array}{l}\text { Maximum displacement of the tower top } \\
\qquad(\mathrm{mm})\end{array}$} & \multicolumn{3}{|c|}{$\begin{array}{l}\text { Maximum displacement in the middle of } \\
\text { the span }(\mathrm{mm})\end{array}$} & \multirow{2}{*}{$\begin{array}{l}\text { Maximum axial force in the middle of } \\
\text { the } \operatorname{span}(\mathrm{kN})\end{array}$} \\
\hline & $\begin{array}{l}\text { Cross } \\
\text { bridge }\end{array}$ & $\begin{array}{l}\text { Longitudinal } \\
\text { direction }\end{array}$ & Vertical & $\begin{array}{l}\text { Cross } \\
\text { bridge }\end{array}$ & $\begin{array}{l}\text { Longitudinal } \\
\text { direction }\end{array}$ & Vertical & \\
\hline Model 1 & 48.31 & 0.003 & 61.18 & 197.05 & 0.74 & 59.55 & $6.24 \times 10^{3}$ \\
\hline Model 4 & 36.72 & 0.003 & 61.24 & 78.69 & 0.75 & 8.07 & $5.68 \times 10^{3}$ \\
\hline Model 5 & 69.11 & 0.006 & 61.38 & 9.87 & 0.72 & 0.42 & $6.89 \times 10^{3}$ \\
\hline
\end{tabular}

displacement in the transverse bridge direction and the maximum vertical displacement in the centre span are both obvious. The decrease indicates that the auxiliary pier has a greater influence on the rigidity of the main girder, and the rigidity of the main girder is increased significantly after the auxiliary pier is added.

Tables 7 and 8 show that the maximum midspan axial force of structural Model 4 is less than the maximum midspan axial force of structural Model 1 and that the midspan maximum axial force of structural Model 1 is less than the maximum midspan axial force of structural Model 5 , which means that when a pair of auxiliary piers are added to both spans of the main girder, the maximum axial force in the midspan of the main girder can be reduced, which is beneficial to the earthquake resistance of the main girder. The number of auxiliary piers is increased to 3 for both spans. In contrast, this is not good for the earthquake resistance of the main beam.

Tables 9 and 10 show that the maximum bending moments of the tower roots in the horizontal and vertical directions of Model 5 correspond to the corresponding bending moments of Model 1 and Model 4 under the excitation of the transverse bridge direction and transverse bridge direction $+1 / 2$ vertical direction. Compared with each other, there is a significant increase, and the maximum bending moment of the longitudinal bridge of these three structural models exhibits little change, which shows that when the number of auxiliary piers reaches 3 pairs for both spans, the main tower root is under an unfavourable state of force.

Tables 9 and 10 show that under horizontal and horizontal $+1 / 2$ vertical excitation, as the number of additional auxiliary piers increases, the maximum bending moment of the main girder in the horizontal and vertical directions decreases. With a small trend, the maximum bending moment of the longitudinal bridge in the middle of the span increases. Although the maximum bending moments in the transverse and vertical directions of structural Model 5 are relatively small, combined with the maximum bending moment response at the root of the tower and the influence of auxiliary piers on the project cost, structural Model 5 is not optimal.

Through the above analysis, it can be seen that under transverse and transverse $+1 / 2$ vertical excitation, the dynamic response value of the structure is small when a pair of auxiliary piers are added to both spans of the main girder, and the seismic performance of the structure is better.

5.2. Seismic Response Analysis of Three Structural Models under Longitudinal Bridge Direction and Longitudinal Bridge Direction $+1 / 2$ Vertical Excitation. The maximum displacement at the top of the tower, the maximum displacement at the centre of the span, and the maximum axial force at the centre of the three structural models under longitudinal bridge direction and longitudinal bridge direction $+1 / 2$ vertical excitation are shown in Tables 11 and 12. The maximum bending moments of the tower root and the centre span are shown in Tables 13 and 14 .

Tables 11 and 12 show that under longitudinal bridge direction and longitudinal bridge direction $+1 / 2$ vertical excitation, the maximum displacements of the tower tops in Models 1, 4, and 5 in the transverse, longitudinal, and vertical directions do not change, indicating that the presence or absence of auxiliary piers and the number of auxiliary piers basically have no effect on the maximum displacement of the tower top in the transverse direction, longitudinal direction, or vertical direction and have little effect on the stiffness of the main tower.

Tables 11 and 12 show that under longitudinal bridge direction and longitudinal bridge direction $+1 / 2$ vertical excitation, with an increasing number of additional auxiliary piers, the maximum vertical displacement in the middle of the span is significantly reduced. With a pair of auxiliary piers, the maximum vertical displacement of the main beam midspan is already within $10 \mathrm{~mm}$, which can meet the needs of the project. Therefore, the presence or absence of auxiliary piers has a greater impact on the rigidity of the main girder. 
TABLE 9: The maximum bending moments of the tower roots and midspans of the three structural models under transverse excitation.

\begin{tabular}{|c|c|c|c|c|c|c|}
\hline \multirow{2}{*}{ Structure type } & \multicolumn{3}{|c|}{ Tower root maximum bending moment $(\mathrm{kN} \cdot \mathrm{m})$} & \multicolumn{3}{|c|}{$\begin{array}{l}\text { Maximum bending moment in the middle of the span } \\
\qquad(\mathrm{kN} \cdot \mathrm{m})\end{array}$} \\
\hline & Cross bridge & Longitudinal direction & Vertical & Cross bridge & Longitudinal direction & Vertical \\
\hline Model 1 & 4.04 & $5.32 \times 10^{4}$ & 3.11 & $2.30 \times 10^{5}$ & $8.99 \times 10^{3}$ & $1.40 \times 10^{5}$ \\
\hline Model 4 & 3.98 & $6.50 \times 10^{4}$ & 2.81 & $8.71 \times 10^{4}$ & $3.87 \times 10^{4}$ & $1.27 \times 10^{5}$ \\
\hline Model 5 & 123.17 & $6.62 \times 10^{4}$ & $1.21 \times 10^{3}$ & $3.32 \times 10^{4}$ & $4.02 \times 10^{4}$ & $4.61 \times 10^{4}$ \\
\hline
\end{tabular}

TABLE 10: The maximum bending moments of the tower roots and midspans of the three structural models under transverse $+1 / 2$ vertical excitation.

\begin{tabular}{|c|c|c|c|c|c|c|}
\hline \multirow[t]{2}{*}{ Structure type } & \multicolumn{3}{|c|}{ Tower root maximum bending moment $(\mathrm{kN} \cdot \mathrm{m})$} & \multicolumn{3}{|c|}{$\begin{array}{l}\text { Maximum bending moment in the middle of the span } \\
\qquad(\mathrm{kN} \cdot \mathrm{m})\end{array}$} \\
\hline & Cross bridge & Longitudinal direction & Vertical & Cross bridge & Longitudinal direction & Vertical \\
\hline Model 1 & 4.02 & $6.48 \times 10^{5}$ & 2.80 & $2.41 \times 10^{5}$ & $9.01 \times 10^{3}$ & $1.37 \times 10^{5}$ \\
\hline Model 4 & 3.96 & $6.41 \times 10^{5}$ & 2.77 & $8.75 \times 10^{4}$ & $3.49 \times 10^{4}$ & $1.28 \times 10^{5}$ \\
\hline Model 5 & 124.02 & $6.59 \times 10^{5}$ & $1.20 \times 10^{3}$ & $3.31 \times 10^{4}$ & $3.88 \times 10^{4}$ & $4.60 \times 10^{4}$ \\
\hline
\end{tabular}

TABLE 11: Displacements and axial forces of the three structural models under longitudinal bridge excitation.

\begin{tabular}{|c|c|c|c|c|c|c|c|}
\hline \multirow{2}{*}{$\begin{array}{l}\text { Structure } \\
\text { type }\end{array}$} & \multicolumn{3}{|c|}{$\begin{array}{l}\text { Maximum displacement of the tower top } \\
\qquad(\mathrm{mm})\end{array}$} & \multicolumn{3}{|c|}{$\begin{array}{l}\text { Maximum displacement in the middle of } \\
\text { the span }(\mathrm{mm})\end{array}$} & \multirow{2}{*}{$\begin{array}{l}\text { Maximum axial force in the middle of } \\
\text { the span }(\mathrm{kN})\end{array}$} \\
\hline & $\begin{array}{l}\text { Cross } \\
\text { bridge }\end{array}$ & $\begin{array}{l}\text { Longitudinal } \\
\text { direction }\end{array}$ & Vertical & $\begin{array}{l}\text { Cross } \\
\text { bridge }\end{array}$ & $\begin{array}{l}\text { Longitudinal } \\
\text { direction }\end{array}$ & Vertical & \\
\hline Model 1 & 0 & 39.51 & 61.30 & 0.071 & 1.76 & 54.59 & $2.37 \times 10^{4}$ \\
\hline Model 4 & 0 & 39.70 & 61.39 & 0.070 & 1.80 & 6.15 & $1.80 \times 10^{4}$ \\
\hline Model 5 & 0 & 39.21 & 61.58 & 0.083 & 1.70 & 0.37 & $2.94 \times 10^{4}$ \\
\hline
\end{tabular}

TABLE 12: Displacements and axial forces of the three structural models under longitudinal bridge direction $+1 / 2$ vertical excitation.

\begin{tabular}{|c|c|c|c|c|c|c|c|}
\hline \multirow{2}{*}{$\begin{array}{l}\text { Structure } \\
\text { type }\end{array}$} & \multicolumn{3}{|c|}{$\begin{array}{l}\text { Maximum displacement of the tower top } \\
\qquad(\mathrm{mm})\end{array}$} & \multicolumn{3}{|c|}{$\begin{array}{l}\text { Maximum displacement in the middle of } \\
\text { the span }(\mathrm{mm})\end{array}$} & \multirow{2}{*}{$\begin{array}{l}\text { Maximum axial force in the middle of } \\
\text { the span }(\mathrm{kN})\end{array}$} \\
\hline & $\begin{array}{l}\text { Cross } \\
\text { bridge }\end{array}$ & $\begin{array}{l}\text { Longitudinal } \\
\text { direction }\end{array}$ & Vertical & $\begin{array}{l}\text { Cross } \\
\text { bridge }\end{array}$ & $\begin{array}{l}\text { Longitudinal } \\
\text { direction }\end{array}$ & Vertical & \\
\hline Model 1 & 0 & 39.52 & 61.18 & 0.071 & 1.99 & 59.98 & $2.34 \times 10^{4}$ \\
\hline Model 4 & 0 & 39.59 & 61.29 & 0.069 & 1.84 & 9.48 & $1.74 \times 10^{4}$ \\
\hline Model 5 & 0 & 39.20 & 61.60 & 0.079 & 1.70 & 0.35 & $2.85 \times 10^{4}$ \\
\hline
\end{tabular}

TABLE 13: Maximum bending moments of the tower roots and midspans of the three structural models under longitudinal bridge excitation.

\begin{tabular}{|c|c|c|c|c|c|c|}
\hline \multirow[t]{2}{*}{ Structure type } & \multicolumn{3}{|c|}{ Tower root maximum bending moment $(\mathrm{kN} \cdot \mathrm{m})$} & \multicolumn{3}{|c|}{$\begin{array}{l}\text { Maximum bending moment in the middle of the span } \\
\qquad(\mathrm{kN} \cdot \mathrm{m})\end{array}$} \\
\hline & Cross bridge & Longitudinal direction & Vertical & Cross bridge & Longitudinal direction & Vertical \\
\hline Model 1 & $7.49 \times 10^{4}$ & $6.71 \times 10^{5}$ & $9.58 \times 10^{4}$ & $2.30 \times 10^{5}$ & $6.89 \times 10^{3}$ & 353.08 \\
\hline Model 4 & $6.18 \times 10^{4}$ & $6.60 \times 10^{5}$ & $8.13 \times 10^{4}$ & $8.71 \times 10^{4}$ & $7.08 \times 10^{3}$ & 389.20 \\
\hline Model 5 & $7.50 \times 10^{4}$ & $6.61 \times 10^{5}$ & $9.61 \times 10^{4}$ & $3.30 \times 10^{4}$ & $7.61 \times 10^{3}$ & 385.51 \\
\hline
\end{tabular}

As the number of auxiliary piers increases, the rigidity of the main girder increases more.

Tables 11 and 12 show that under longitudinal bridge direction and longitudinal bridge direction $+1 / 2$ vertical excitation, the maximum midspan axial force of structural Model 4 is less than the maximum midspan axial force of structural Model 1, and the midspan maximum axial force of structural Model 1 is less than the maximum axial force in the middle of the structure Model 5, which means that when a pair of auxiliary piers are added to the two spans of the main girder, the maximum axial force in the middle of the main girder can be reduced, benefitting the seismic resistance of the main girder. The number of auxiliary piers reaches both spans. The 3 pairs are disadvantageous to the seismic resistance of the main beam.

Tables 13 and 14 show that under the excitation of the longitudinal bridge direction and longitudinal bridge direction $+1 / 2$ vertical direction, the maximum bending 
TABle 14: Maximum bending moments of the tower root and midspan of the three structural models under longitudinal bridge direction $+1 / 2$ vertical excitation.

\begin{tabular}{lccccc}
\hline \multirow{2}{*}{$\begin{array}{l}\text { Structure type } \\
\end{array}$} & \multicolumn{2}{c}{ Tower root maximum bending moment $(\mathrm{kN} \cdot \mathrm{m})$} & \multicolumn{2}{c}{ Maximum bending moment in the middle of the span } \\
& Cross bridge & Longitudinal direction & Vertical & Cross bridge & Longitudinal direction \\
\hline Model 1 & $7.59 \times 10^{4}$ & $6.49 \times 10^{5}$ & $1.04 \times 10^{5}$ & $2.19 \times 10^{5}$ & $6.88 \times 10^{3}$ \\
Model 4 & $6.17 \times 10^{4}$ & $6.58 \times 10^{5}$ & $8.08 \times 10^{4}$ & $9.18 \times 10^{4}$ & 352.22 \\
Model 5 & $7.51 \times 10^{4}$ & $6.62 \times 10^{5}$ & $9.59 \times 10^{4}$ & $3.28 \times 10^{4}$ & $7.62 \times 10^{3}$ \\
\hline
\end{tabular}

moment of the tower root in the transverse direction and the vertical direction of structure Model 4 is the smallest, indicating that the addition of 1 pair of piers to the two spans of the main girder is beneficial to the seismic resistance of the main tower. When 3 pairs of auxiliary piers are added to the two spans of the main beam, the seismic performance of the main tower decreases instead. The maximum bending moments of the tower root in the longitudinal direction of the three structural models are relatively close, indicating that the presence or absence of auxiliary piers and the number of additional auxiliary piers have no effect on the maximum vertical bending moment of the tower root.

Tables 13 and 14 show that under longitudinal bridge direction and longitudinal bridge direction $+1 / 2$ vertical excitation, as the number of additional auxiliary piers increases, the maximum bending moment of the main girder in the midspan transverse bridge direction shows a downward trend. The maximum bending moment in the longitudinal direction of the midspan gradually increases, and the maximum vertical bending moment in the midspan shows little change. Although the seismic response of the main girder of structural Model 5 is relatively small under the excitation of seismic waves, combined with the bending moment response at the root of the tower and the influence of auxiliary piers on the project cost, structural Model 5 is not optimal.

With the application of seismic waves in the transverse bridge direction, longitudinal bridge direction, transverse bridge direction $+1 / 2$ vertical, and longitudinal bridge direction $+1 / 2$ vertical in Model 1 , Model 4 , and Model 5, the research on the displacement response and internal force response of the main girder shows that the number of auxiliary piers has a great influence on the midspan vertical displacement of the main girder but has little effect on the vertical displacement of the main tower; an appropriate number of auxiliary piers is beneficial to the seismic resistance of the cable-stayed bridge. When the number of auxiliary piers is too large, it is detrimental to the seismic performance of the cable-stayed bridge. In actual engineering, it is recommended to add a pair of auxiliary piers to both spans of the main girder to optimize the overall seismic performance of the cable-stayed bridge.

\section{Conclusion}

Based on the Guohe Third Bridge in Anhui Province, a finite element model of a long-span cable-stayed bridge with a specially shaped mixed steel structure main tower was established. With the addition of auxiliary piers, the natural vibration frequency, deformation characteristics, displacements and internal forces of the related parts of the whole bridge were analysed. The following conclusions are drawn:

(1) When auxiliary piers are added to a single span, the natural frequency and deformation characteristics of the cable-stayed bridge structure change relatively little; when auxiliary piers are added to both spans, the natural frequency and deformation characteristics of the cable-stayed bridge structure change relatively greatly.

(2) A comparison of the addition of 3 pairs of auxiliary piers to a single span and 1 pair to a single span with the addition of 3 pairs of auxiliary piers to both spans and 1 pair to both spans shows that the changes in natural frequency and deformation characteristics are relatively small. The addition of 3 pairs of auxiliary piers to both spans results in excessive rigidity of the main girder, unreasonable stiffness distribution of the cable-stayed bridge, and high cost.

(3) The presence or absence of auxiliary piers and the number of auxiliary piers have little effect on the vertical displacement of the main tower and have a greater impact on the midspan displacement of the main girder. The auxiliary piers greatly increase the stiffness of the main girder. A proper number of auxiliary piers are beneficial to the force state of the cable-stayed bridge. When the number of auxiliary piers reaches 3 pairs for both spans, the seismic performance of the structure decreases instead.

(4) Considering the reasonable force of the cablestayed bridge and the project cost of adding auxiliary piers, it is recommended to use the structure form of a pair of auxiliary piers on both spans to coordinate the rigidity of the main tower and the main girder in the actual project. Under the excitation of seismic waves, the overall response is small, which enhances the seismic performance of the cable-stayed bridge.

(5) For similar cable-stayed bridges, the research method of this study can be used to optimize the dynamic performance of cable-stayed bridges by setting a certain number of auxiliary piers.

\section{Data Availability}

The data used to support the findings of this study are included within the article. 


\section{Conflicts of Interest}

The authors declare that they have no conflicts of interest.

\section{Acknowledgments}

Guangxi Key Laboratory of disaster prevention and engineering safety, Guangxi University. Project name: supported by the Systematic Project of Guangxi Key Laboratory of Disaster Prevention and Engineering Safety (2020ZDK001).

\section{References}

[1] C. Yang, Design and Analysis of Steel-Hybrid Combined Box Girder cable-stayed Bridge with Single cable Deck, Zhejiang University, Zhejiang, China, 2018.

[2] Z. Mei, Research on Construction Monitoring of Steel Main Towers of Shaped cable-stayed Bridges, Lanzhou Jiaotong University, Lanzhou, China, 2017.

[3] P. Saha and R. S. Jangid, "Seismic control of benchmark cablestayed bridge using variable sliding isolators," Journal of Structural Engineering, vol. 43, no. 1, pp. 79-99, 2016.

[4] Z. Fan, L. Shuai, Y. Xiaowei, and W. Jingquan, "Effects of near- fault pulse-type ground motions on long-span cablestayed bridge," Journal of Vibration and Shock, vol. 36, no. 21, pp. 164-165, 2017.

[5] X. Cai, Z. Zhou, H. Zang, and Z. Song, "Water saturation effects on dynamic behavior and microstructure damage of sandstone: phenomena and mechanisms," Engineering Geology, vol. 276, Article ID 105760, 2020.

[6] X. Cai, Z. Zhou, and X. Du, "Water-induced variations in dynamic behavior and failure characteristics of sandstone subjected to simulated geo-stress," International Journal of Rock Mechanics and Mining Sciences, vol. 130, Article ID 104339, 2020.

[7] Y. Jiang, L. Chuang, and L. Jianzhong, "Influence of ground motion frequency characteristics on longitudinal seismic response of single tower cable-stayed bridges," Journal of Tongji University, vol. 45, no. 8, pp. 1114-1115, 2017.

[8] L. Yongxing, Y. Jiang, and L. Jianzhong, "Effects of auxiliary piers on unseating of a cable-stayed bridge under earthquakes," Journal of Vibration and Shock, vol. 38, no. 15, pp. 95-102, 2019.

[9] Y. Mei, L. Qiao, and L. A. Haili, "Effect of subsidiary piers on mechanical behavior of multi-pylon cable-stayed bridges," World Bridge, no. 3, pp. 36-39, 2010.

[10] Y. Xiyao, Influence of Auxiliary Piers on Mechanical Properties of Single-tower cable-stayed Bridges, Hefei University of Technology, Hefei, China, 2014.

[11] P. M. Huang and X. Z. Liu, "Analysis of dynamic characteristics of single-tower cable-stayed bridges under different boundary conditions," Highways, no. 8, pp. 1-4, 2007.

[12] S. Liu, Analysis of the Influence of Structural Parameter Changes on the Seismic Response of Six-tower cable-stayed Bridges, Southwest Jiaotong University, Chengdu, China, 2013.

[13] X. Fan, Research on the Optimal Setting of Auxiliary Piers for High-Low tower cable-stayed Bridges, Chang'an University, Xi'an, China, 2016.

[14] W. Wang, Y. F. Huang, C. Zhou, and S. Q. Zhu, "Effect of auxiliary pier on double upright tower cable-stayed bridge without upper crossbeam," China and Foreign Highway, vol. 32, no. 5, pp. 119-123, 2012.
[15] X. Wang, ANSYS Numerical Analysis of Engineering Structures, People's Traffic Publishing House, Beijing, China, 2007.

[16] X. Du, H. Fang, S. Wang, B. Xue, and F. Wang, "Experimental and practical investigation of the sealing efficiency of cement grouting in tortuous fractures with flowing water," Tunnelling and Underground Space Technology, vol. 108, Article ID 103693, 2021. 